Neurosurg Focus 18 (2):E4, 2005

\title{
Treatment of wide-necked cerebral aneurysms with the Neuroform2 Treo stent
}

\author{
A prospective 6-month study
}

\author{
SePehr Sani, M.D., Kirk W. Jobe, M.D., and Demetrius K. LoPes, M.D. \\ Department of Neurosurgery, Rush University Medical Center, Chicago, Illinois
}

\begin{abstract}
Object. Until recently, wide-necked aneurysms were not considered amenable to treatment with coil embolization. The recent introduction of intracranial stents has provided a method of preventing coil migration out of wide-necked aneurysms. The Neuroform 2 Treo is a modification of the Neuroform stent; the new version has a higher metal/artery ratio. The authors' initial experience with the use of this stent in combination with coil embolization to treat widenecked intracranial aneurysms is reported and technical considerations are discussed.

Methods. The authors' first 10 consecutive patients with wide-necked intracranial aneurysms were included in this study. Inclusion criteria restricted the group to adult patients with wide-necked intracranial aneurysms (ruptured and unruptured lesions). A wide neck was defined as a dome/neck ratio of less than 2 or a neck that was 4 mm or wider as measured on angiograms. Immediate postprocedure angiography studies were performed to determine successful coil occlusion of the aneurysm as well as patency of the parent vessel. Six-month follow-up angiograms were obtained in all patients.

Ten aneurysms with poor dome/neck ratios $(<2)$ were studied in 10 patients. In all cases the stent was delivered to the aneurysm site and positioned without difficulty. No branch artery compromise was observed. A technical difficulty occurred in one case, with prolapse of a coil into the parent vessel, which was successfully corrected with no adverse clinical effects. There were no clinical or neurological complications associated with endovascular treatment of aneurysms in this series. One patient required further coil embolization because of findings on the 6-month follow-up cerebral angiogram.

Conclusions. The Neuroform 2 Treo navigates similarly to the Neuroform2, with the advantage of increased aneurysm neck coverage. This feature may lower the retreatment rates for wide-necked cerebral aneurysms.
\end{abstract}

\author{
KEY WordS - endovascular therapy \\ stent insertion - coil occlusion
}

- aneurysm - Neuroform2 Treo stent •
In this article we review our experience using the Neuroform2 Treo stent (Boston Scientific/Target, Fremont, CA). This stent, with its open-cell design, is similar to the Neuroform2 device, but contains a modified geometry that increases the aneurysm neck coverage. Ten patients with wide-necked aneurysms, defined as a neck/dome ratio of less than 2 or a neck wider than $4 \mathrm{~mm}$, were treated.

In all cases the stent was delivered to the aneurysm site and deposited without difficulty. Complete angiographically confirmed occlusion of the aneurysm was obtained, and normal distal flow was noted. No branch artery compromise was observed. A technical difficulty occurred in one case, with a coil partially prolapsing into the parent vessel, which was successfully repaired by superimposing a second Neuroform2 Treo stent over the one previously deposited. The coil was then trapped between the stents.

Abbreviations used in this paper: $\mathrm{ACoA}=$ anterior communicating artery; $\mathrm{SAH}=$ subarachnoid hemorrhage.
There were no treatment-related clinical or neurological complications associated with endovascular occlusion of aneurysms in this series. Six-month follow-up angiography revealed no parent vessel compromise. One patient required completion of coil embolization at 6-month follow-up review. The Neuroform 2 Treo system seems to have the deliverability of the Neuroform2, with the advantage of increased aneurysm neck coverage. The 6-month follow-up review constituted a test for the durability of the stent and coil construction.

Endovascular treatment of cerebral aneurysms has advanced significantly in recent years. Improvements in products and methods for coil embolization of cerebral aneurysms are providing favorable outcomes, and followup studies are revealing comparable results with surgical clip ligation. ${ }^{7}$

Until recently, wide-necked aneurysms were not considered amenable to coil embolization. ${ }^{2,12}$ Placement of expandable stents through the parent vessel as a scaffold 
across the neck of the aneurysm held promise because it prevented coil migration out of the lesion. ${ }^{11}$ Nevertheless, the initial experience with balloon-mounted coronary stents was disappointing because they were usually difficult to navigate through the tortuous intracranial vasculature. ${ }^{5,8,15}$ The introduction of the first flexible intracranial stent (Neuroform; Boston Scientific/Target) and recent publication of preliminary series detailing the experience of various investigators in treating wide-necked aneurysms are proving this device to be effective in treating pathological entities that were previously not considered amenable to endovascular therapy. ${ }^{1,4,6,16}$

Recently, the new-generation intracranial stent, called the Neuroform2 Treo, was introduced. This stent, with its open-cell design, is similar to the Neuroform, but contains a modified geometry. The rings of the stent are connected with an extra tine, which decreases the area of the open cells by $39 \%$. The preliminary experience with the use of this stent in combination with coil insertion in treating wide-necked intracranial aneurysms is reported and technical considerations are discussed.

\section{CLINICAL MATERIAL AND METHODS}

\section{Demographic Data and Inclusion Criteria}

Demographic data were obtained and recorded for each patient. Aneurysm location, size, and indication for treatment were recorded. In addition, technical information regarding stent delivery, implantation, and any complications were collected. Ten consecutive patients with widenecked intracranial aneurysms were included in this study. All cases were evaluated by our vascular team. The options of observation, clip ligation, and endovascular repair were considered in all cases. Inclusion criteria restricted the group to adult patients with wide-necked intracranial aneurysms (ruptured and unruptured). A wide neck was defined as a dome/neck ratio of less than 2 or a neck that was $4 \mathrm{~mm}$ or wider as measured on angiographic images. A signed informed consent was obtained from each patient.

\section{Patient Population}

Ten patients (six of whom were women) with 10 aneurysms were treated as shown in Table 1 . The mean age at the time of treatment was 53.6 years (range 37-70 years). Three patients had previously ruptured aneurysms and were treated with staged embolization. All lesions were wide-necked and the majority were located in the anterior circulation. One aneurysm was located in the junction of the basilar artery and superior cerebellar artery, one in the ACoA, two each in the posterior communicating artery and cavernous carotid artery, and four in the carotid ophthalmic artery. The mean neck size was $4.1 \mathrm{~mm}$ (range 3-5 $\mathrm{mm}$ ) and all lesions demonstrated poor neck/dome ratios $(<2)$. The mean dome diameter was $5.2 \mathrm{~mm}$. All the unruptured aneurysms were treated with Neuroform2 Treo stents placed across the neck of the lesion prior to coil embolization. As mentioned previously, the three ruptured aneurysms were treated in a staged fashion.

Angiographic studies obtained in all aneurysms were reviewed by the attending endovascular neurosurgeon (D.K.L.) and the lesions were found to have unfavorable dome/neck ratios $(<2)$ for treatment by coil embolization alone.

\section{Stent Delivery Method}

All patients were treated electively and received antiplatelet pharmacotherapy (325 mg aspirin and $75 \mathrm{mg}$ clopidogrel daily) starting 3 days before the procedure. Therapy was continued for 3 months posttreatment. Intraoperative heparinization to an activated clotting time of 250 seconds was achieved for the duration of the procedure.

After diagnostic angiography was performed, working views were obtained for stent delivery. The appropriate Neuroform Treo stent size was selected (available diameters were $2.5-4.5 \mathrm{~mm}$ and lengths were $10-30 \mathrm{~mm}$ ) such that the stent diameter was $0.5 \mathrm{~mm}$ larger than the parent vessel diameter and the ends of the device would extend at least $5 \mathrm{~mm}$ beyond the neck of the aneurysm on each side.

A No. 6 French guiding catheter (Cordis Neurovascular, Miami Lakes, FL) was advanced to the cervical segment of the target vessel. We used the single-operator technique for delivery of the stents (the stent delivery system was used as a microcatheter). The Neuroform2 Treo stent delivery system was flushed with saline, and then a Synchro 14 (Boston Scientific) 200-cm microguidewire was backloaded into the stent delivery catheter.

TABLE 1

Summary of data in 10 patients treated with Neuroform2 Treo stents*

\begin{tabular}{|c|c|c|c|c|c|c|}
\hline $\begin{array}{c}\text { Case } \\
\text { No. }\end{array}$ & $\begin{array}{c}\text { Age (yrs), } \\
\text { Sex }\end{array}$ & $\begin{array}{l}\text { Aneurysm } \\
\text { Location }\end{array}$ & $\begin{array}{l}\text { Aneurysm } \\
\text { Size }(\mathrm{mm})\end{array}$ & $\begin{array}{c}\text { Stent } \\
\text { Position }\end{array}$ & $\begin{array}{c}\text { Immediate } \\
\text { FU }\end{array}$ & $\begin{array}{c}\text { 6-Mo } \\
\text { FU }\end{array}$ \\
\hline 1 & $46, \mathrm{~F}$ & rt SCA & $4 \times 6$ & BA, rt SCA & resid & resid \\
\hline 2 & $70, \mathrm{M}$ & lt carotid OphA & $4 \times 4$ & lt ICA, supraclinoidal & comp & comp \\
\hline 3 & $50, \mathrm{~F}$ & lt $\mathrm{PCoA}$ & $8 \times 4$ & lt ICA, supraclinoidal & comp & comp \\
\hline 4 & $52, \mathrm{~F}$ & lt cavernous $\mathrm{CA}$ & $6 \times 5$ & lt ICA, clinoidal & comp & comp \\
\hline 5 & $55, \mathrm{M}$ & rt carotid OphA & $5 \times 4$ & rt ICA, supraclinoidal & comp & comp \\
\hline 6 & $37, \mathrm{~F}$ & lt carotid OphA & $4 \times 4$ & lt ICA, supraclinoidal & comp & comp \\
\hline 7 & $43, \mathrm{~F}$ & rt carotid OphA & $3 \times 4$ & rt ICA, supraclinoidal & comp & comp \\
\hline 8 & $67, \mathrm{M}$ & rt PCoA & $4 \times 4$ & rt ICA, supraclinoidal & comp & comp \\
\hline 9 & $55, \mathrm{~F}$ & rt cavernous CA & $6 \times 4$ & rt ICA, clinoidal & comp & comp \\
\hline 10 & $61, \mathrm{M}$ & lt $\mathrm{ACoA}$ & $6 \times 5$ & lt $\mathrm{A}_{1}, \mathrm{ACoA}$ & comp & comp \\
\hline
\end{tabular}

* Comp = complete angiographically confirmed occlusion; $\mathrm{FU}=$ follow up; resid = residual neck present. 
(The Synchro microguidewire tip had been shaped with a mandril.) The stent delivery system was navigated like a microcatheter under roadmap guidance. Once the stent delivery system was advanced beyond the aneurysm neck, the microguidewire was removed and the stent was deposited across the neck of the lesion with a coil pusher or stabilizer.

Proximal and distal placement within the parent vessel were confirmed by visualization of the four platinum marker bands at each end of the stent. The coil pusher and delivery catheters were then removed. The microguidewire was advanced through the interstices of the stent into the aneurysm, followed by the SL 10 microcatheter (Boston Scientific). Aneurysm embolization with detachable Matrix coils commenced according to standard procedures.

\section{Staged Stent Insertion and Coil Embolization}

The initial treatment stage involved partial coil occlusion of the aneurysm. The second stage, performed after the patient recovered from SAH, consisted of stent insertion and further coil embolization. At the second treatment, the patient could then be safely premedicated with the antiplatelet regimen recommended for intracranial stent placement.

\section{RESULTS}

Angiography was used immediately after the procedure to determine the success and degree of coil occlusion as well as patency of the parent vessel. All treated cases demonstrated full patency of the parent vessel and normal distal flow. Complete and satisfactory angiographically confirmed occlusion after stent placement was obtained in nine aneurysms.

Six-month follow-up angiography revealed persistent aneurysm occlusion without parent vessel stenosis in nine patients. In the other patient (Case 1), who had undergone staged therapy after SAH, the lesion could not be completely occluded after stent and coil insertion (second stage). We decided to perform follow-up review with angiography after 6 months and to rely on a possible hemodynamic effect from the stent to achieve complete aneurysm occlusion. On follow-up review there was still a residual lesion. The aneurysm was then completely occluded with coils.

\section{ILLUSTRATIVE CASE}

\section{Stent Placement and Coil Embolization}

In this 61-year-old man (Case 10, Fig. 1), an ACoA aneurysm was diagnosed after he underwent evaluation for headache with magnetic resonance imaging. Diagnostic angiography revealed a wide-necked aneurysm and the patient elected to undergo treatment by endovascular methods. A $4.5 \times 15-\mathrm{mm}$ Neuroform Treo stent was successfully implanted from the ipsilateral $A_{1}$ to the ipsilateral $\mathrm{A}_{2}$ segment. Complete, angiographically confirmed occlusion of the aneurysm was obtained with some light coil packing in the proximal neck (outflow zone). A postprocedure angiogram revealed patent distal vasculature and the patient was discharged home the following day. He returned for a 6-month follow-up angiogram (Fig. 1), which was negative for residual aneurysm neck or parent vessel stenosis.

\section{Technical Difficulties}

Navigation of the stent delivery system was accomplished without difficulty through the tortuous petrous internal carotid artery and a tortuous vertebral artery. In all cases, stent delivery was also performed without difficulty. No branch artery occlusion was demonstrated angiographically. Microcatheter manipulation during coil embolization of the aneurysm did not cause stent mobility, based on monitoring by the proximal and distal markers.

All unruptured aneurysms underwent coil occlusion in the same setting as stent placement. Navigation of the microcatheter through the interstices of the stent was easily accomplished in all cases. In one case, coil packing through the stent initially resulted in partial prolapse of coil material into the parent vessel. A second stent (Neuroform2 Treo) was delivered to trap the prolapsed coil between both devices. On postprocedure angiography, there was no evidence of parent vessel compromise and the patient suffered no clinical sequelae.

\section{Complications Encountered}

There were no clinical or neurological complications associated with endovascular treatment of aneurysms in this series. Immediate postprocedure angiography findings were consistent with patent parent vessel and baseline distal flow. A technical difficulty occurred in one case as described earlier, in which a coil prolapsed into the parent vessel, which was successfully corrected with no clinically adverse effects.

\section{DISCUSSION}

The original Neuroform device (Fig. 2 left) was introduced as the first flexible stent designed for treatment of intracranial wide-necked and fusiform aneurysms. The system is composed of an open-cell design with two connectors between adjacent segments. This allows for significant flexibility and decreases the likelihood of branch vessel obstruction. The Neuroform system subsequently underwent structural revision to improve the delivery characteristics of the stent and was reintroduced as Neuroform2.

The Neuroform 2 Treo is the latest version (Fig. 2 right), and involves the same open-cell design as the Neuroform2, but has three connectors between adjacent segments. The additional connector provides a $39 \%$ decrease in the area of the open cells. It also helps to keep the segments of the stent together, especially in aneurysms located in a vessel curvature. These features allow better parent vessel scaffolding to prevent coil prolapse and to improve "bridging" of endothelial cells across the aneurysm neck.

Metal surfaces of the stent are thrombogenic, and if left untreated, platelet aggregates form on the struts of the stent, leading to thrombus formation and vessel occlusion. ${ }^{4,13}$ Therefore, antiplatelet therapy is initiated before the procedure and continued for 3 months afterward. ${ }^{9}$ This 


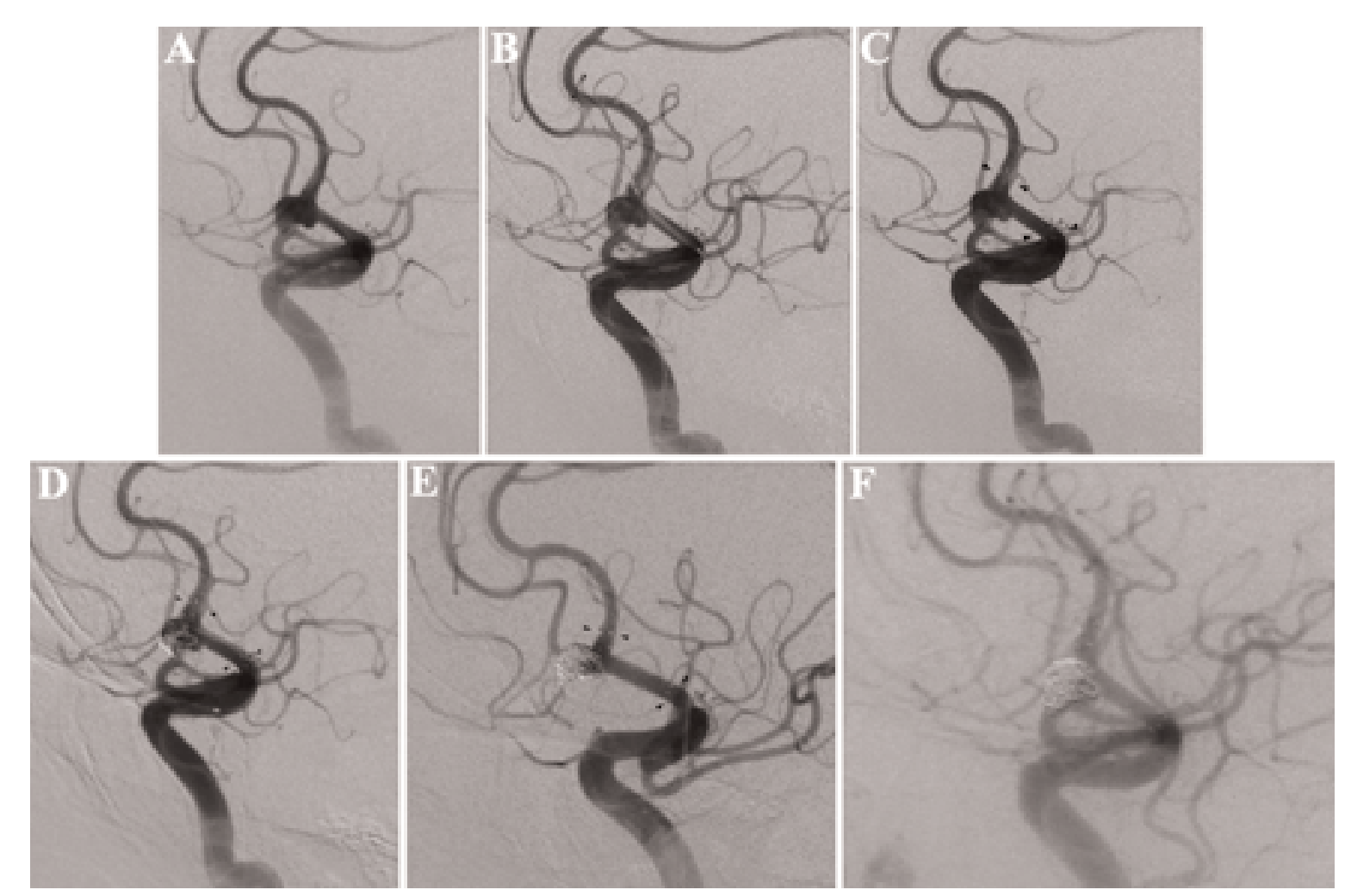

Fig. 1. Case 10. Left selective internal carotid artery cerebral angiograms, oblique view. A: A $6 \times 5$-mm widenecked ACoA aneurysm is demonstrated. B: Same view demonstrating the microcatheter advanced past the aneurysm neck into the ipsilateral $\mathrm{A}_{2}$ segment. C: Successful stent delivery; proximal and distal markers are designated by arrowheads in this and the next two panels. D: Coil embolization of the aneurysm through the interstices of the implanted stent. E: Complete coil embolization of the aneurysm. F: Six-month follow-up angiogram demonstrating no evidence of residual neck or angiographic parent vessel stenosis.

was presumed to be enough time for endothelialization of the stent's metallic struts. ${ }^{3,10,14}$ Confirmation was recently provided in a post mortem human histological study demonstrating complete endothelialization of the stent with significant new fibroelastic tissue formation across the neck of the aneurysm (unpublished data). Although tis- sue formation across the neck was incomplete, it was postulated that a higher metal/artery ratio would lead to complete endothelialization of the aneurysm neck, given enough time (bridge effect). No thrombogenic complications were observed in this series. It should be noted, however, that in the setting of acute SAH the use of antiplatelet
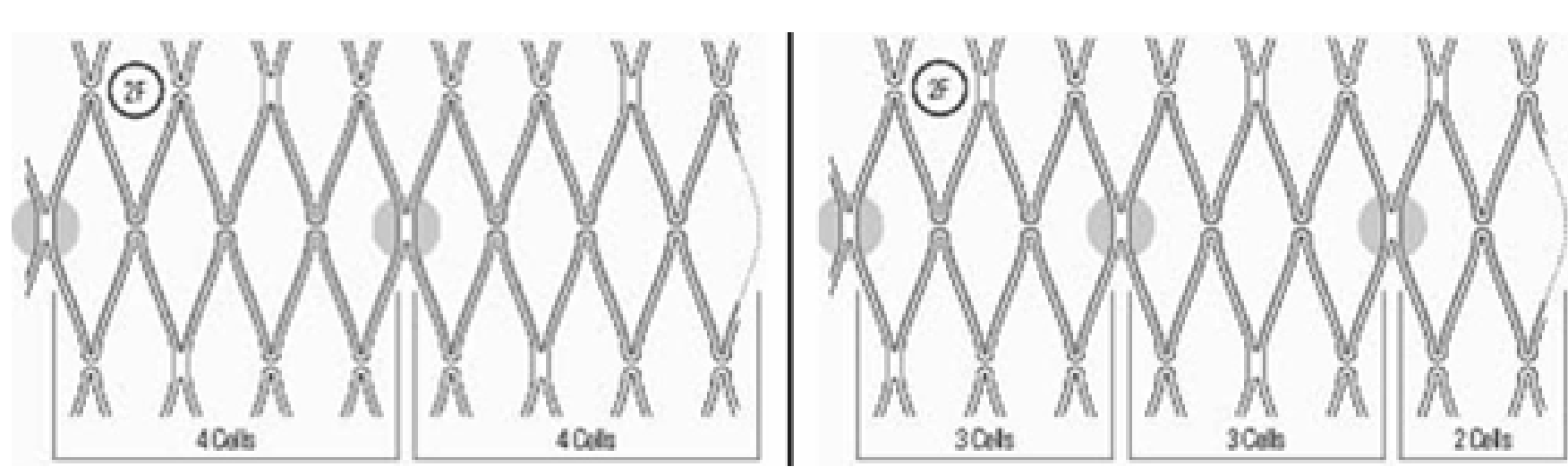

Fig. 2. Illustrations showing the difference between two types of Neuroform stents. Left: The Neuroform2 stent is composed of an open-cell design with two connectors between adjacent segments. Right: The Neuroform2 Treo design is composed of three connectors between adjacent segments, providing a $39 \%$ reduction in the area of the open cells. 


\section{Treatment of wide-necked aneurysms with the Neuroform 2 Treo stent}

therapy may increase morbidity. We recommend a staged approach (partial coil embolization, followed by stent and coil insertion after antiplatelet therapy can be safely administered).

Navigation of the Neuroform2 Treo stent delivery system proved to be very feasible. Even across tortuous segments of the carotid artery siphon or the vertebral artery, the trackability was similar to the Neuroform2 system (single-operator method).

The results of 6-month follow-up angiography were consistent with continued occlusion of the completely coil-filled aneurysms and no parent vessel stenosis. It is still questionable whether this stent can achieve a hemodynamic effect sufficient to occlude a partially embolized aneurysm. Our experience with the patient in Case 1 was not positive. At this point, the goal should be to obtain complete coil occlusion of the aneurysm.

\section{CONCLUSIONS}

The Neuroform 2 Treo system is feasible, safe, and effective in treating wide-necked intracranial aneurysms. Despite the higher metal/artery ratio, there appears to be no increased incidence of acute thrombogenicity or difficulty with vascular navigation. The 6-month follow-up review demonstrated persistent obliteration of the completely treated wide-necked aneurysms, without parent vessel compromise. Larger series and longer follow-up intervals are needed to elucidate the long-term efficacy and prognosis for aneurysms treated with the Neuroform 2 Treo stent. Our results are encouraging because they demonstrate that devices like the Neuroform 2 Treo will continue to improve our ability to treat wide-necked aneurysms with lower morbidity and mortality and retreatment rates.

\section{References}

1. Broadbent LP, Moran CJ, Cross DT III, et al: Management of neuroform stent dislodgement and misplacement. AJNR 24: 1819-1822, 2003

2. Cognard C, Weill A, Spelle L, et al: Long-term angiographic follow-up of 169 intracranial berry aneurysms occluded with detachable coils. Radiology 212:348-356, 1999

3. Ferns GA, Stewart-Lee AL, Anggard EE: Arterial response to mechanical injury: balloon catheter de-endothelialization. Atherosclerosis 92:89-104, 1992
4. Fiorella D, Albuquerque FC, Han P, et al: Preliminary experience using the Neuroform stent for the treatment of cerebral aneurysms. Neurosurgery 54:6-17, 2004

5. Han PP, Albuquerque FC, Ponce FA, et al: Percutaneous intracranial stent placement for aneurysms. J Neurosurg 99:23-30, 2003

6. Howington JU, Hanel RA, Harrigan MR, et at: The Neuroform stent, the first microcatheter-delivered stent for use in the intracranial circulation. Neurosurgery 54:2-5, 2004

7. International Subarachnoid Aneurysm Trial (ISAT) Collaborative Group: International Subarachnoid Aneurysm Trial (ISAT) of neurosurgical clipping versus endovascular coiling in 2143 patients with ruptured intracranial aneurysms: a randomized trial. Lancet 360:1267-1274, 2002

8. Lanzino G, Wakhloo AK, Fessler RD, et al: Efficacy and current limitations of intravascular stents for intracranial internal carotid, vertebral, and basilar artery aneurysms. J Neurosurg 91:538-546, 1999

9. Leon MB, Baim DS, Popma JJ, et al: A clinical trial comparing three antithrombotic-drug regimens after coronary-artery stenting. N Engl J Med 339:1665-1671, 1998

10. Lijnen HR, Collen D: Endothelium in hemostasis and thrombosis. Prog Cardiovasc Dis 39:343-350, 1997

11. Moret J, Cognard C, Weill A, et al: [Reconstruction technic in the treatment of wide-neck intracranial aneurysms. Long-term angiographic and clinical results. Apropos of 56 cases.] J Neuroradiol 24:30-44, 1997 (Fre)

12. Murayama Y, Nien YL, Duckwiler G, et al: Guglielmi detachable coil embolization of cerebral aneurysms: 11 years' experience. J Neurosurg 98:959-966, 2003

13. Qureshi AI, Luft AR, Sharma M, et al: Prevention and treatment of thromboembolic and ischemic complications associated with endovascular procedures: Part I-Pathophysiological and pharmacological features. Neurosurgery 46:1344-1359, 2000

14. Van Belle E, Tio FO, Chen D, et al: Passivation of metallic stents after arterial gene transfer of ph VEGF165 inhibits thrombus formation and intimal thickening. J Am Coll Cardiol 29:1371-1379, 1997

15. Wakhloo AK, Lanzino G, Lieber BB, et al: Stents for intracranial aneurysms: the beginning of a new endovascular era? Neurosurgery 43:377-379, 1998

16. Wanke I, Doerfler A, Schoch B, et al: Treatment of widenecked intracranial aneurysms with a self-expanding stent system: initial clinical experience. AJNR 24:1192-1199, 2003

Manuscript received January 13, 2005.

Accepted in final form January 21, 2005.

Address reprint requests to: Demetrius Klee Lopes, M.D., Department of Neurosurgery, Rush University Medical Center, 1725 West Harrison Street, Suite 1115, Chicago, Illinois 60612. email: dlopes@neurosource.com. 